\title{
THE BIOPHYSICAL CHARACTERISTICS AND STRUCTURAL EXPLORATION OF PROGRAMMED CELL DEATH REGULATOR B-CELL LYMPHOMA 2-ASSOCIATED X PROTEIN OF CHINESE LIVER FLUKE (CLONORCHIS SINENSIS)
}

\author{
SUBHAMAY PANDA ${ }^{1,2 *}$, DIPAK PRASAD ${ }^{1}$, INDRANIL BAG \\ ${ }^{1}$ Department of Pharmacy, Gupta College of Technological Sciences, Ashram More, Asansol, West Bengal, India. ${ }^{2}$ Department of Biological \\ Sciences, Indian Institute of Human and Social Sciences, Sitarampur, Asansol, West Bengal, India. Email: subhamay_panda@rediffmail.com
}

Received: 10 April 2017, Revised and Accepted: 3 May 2017

\section{ABSTRACT}

Objective: The balance between deaths and cellular life is regulated by B-cell lymphoma 2 (BCL-2)-associated X protein (BAX) an important proapoptotic components of BCL-2 family. With this initial point, the aim of this study was to determine a comparative composite based structure of BAX of Chinese liver fluke and different structural analysis.

Methods: Protein amino acid of BAX of Chinese liver fluke mined from National Centre for Biotechnology Information (http://ncbi.nlm.nih.gov). Molecular model of BAX of Chinese liver fluke protein was generated by the comparative composite modeling tool Iterative Threading ASSEmbly Refinement suite. Afterward, I-TASSER generated molecular model was subjected to further structural improvements by energy minimization step. Distribution of negatively and positively charged amino acid over molecular modeled structure, distribution of secondary structural elements, and hydrophobicity molecular surface analysis was performed with the help of bioinformatical tools.

Results: Analysis of Ramachandran plot created by PROCHECK tool is a consensus standard for validation purpose of protein structural modeling. Altogether $97.8 \%$ of the residues were detected in allowed and favored regions, which in turn validate the quality of generated protein structural model. Total negatively and positively charged residues within the BAX of Chinese liver fluke were 23 and 20, respectively. Chimera package-guided hydrophobicity molecular surface analysis illustrates that molecule specific hydrophobicity surface is exclusive to BAX protein molecule.

Conclusion: Within the scope of this scientific investigation, we have successfully utilized molecular modeling approach to suggest the first molecular three-dimensional model structure of BAX of Chinese liver fluke. The synchronous balance between cellular deaths and cellular life is keeping up by BAX, an important pro-apoptotic family member of BCL-2 family. Consequently, it would be an exciting approach to resolve its structural characterization and molecular structure to propose mode of mechanism action.

Keywords: B-cell lymphoma 2-associated X protein, Chinese liver fluke, Molecular model, Clonorchis sinensis, Protein structure.

(c) 2017 The Authors. Published by Innovare Academic Sciences Pvt Ltd. This is an open access article under the CC BY license (http://creativecommons. org/licenses/by/4. 0/) DOI: http://dx.doi.org/10.22159/ajpcr.2017.v10i7.19063

\section{INTRODUCTION}

B-cell lymphoma 2 (BCL-2)-associated X protein (BAX) was identified as a regulator of cell death that controls apoptosis in normal and cancer cells. BAX is a vital key role player to mitochondrial dysfunctioning and a lead proapoptotic member of the BCL-2 family proteins. Apoptosis dysfunction leads to the cancerous cell becoming resistant to cure and thereby promoting tumorigenesis [1,2]. Activation of BAX induces permeabilization of mitochondrial membrane, thus leading to liberation of apoptotic factor cytochrome $\mathrm{c}$ and as a result death of cancer producing cells. In clinical use, numerous drugs are identified which in some way activates BAX. The proteins in BCL-2 family including BAX and BCL-2 homologous antagonist/killer normally act on the outer mitochondrial membrane to promote permeabilization and commit cells to apoptosis. The continuous retrotranslocation of healthy cells in cytosol controls BAX a pro-survival BCL-2 protein [1-3].

The balance between deaths and cellular life is regulated by BAX an important proapoptotic components of BCL-2 family. Since numerous medical circumstances can be grouped under diseases so some high priority scientific strategies needed to be developed this can pharmacologically target and break down the biochemistry of BCL-2 family [4]. In 1984, BCL-2 family founding member was discovered, as soon as a pediatric patient was diagnosed with acute lymphoblastic leukemia resultant cell line proved that it contain defective oncogenic translocation which merged with the heavy chain of immunoglobulin locus on chromosome 14 with BCL-2 gene on chromosome 18 with unidentified function [5]. In follicular lymphoma, the gene product t $(14 ; 18)$ breakpoint was identified, characterized, cloned [6-8], and discovered that it promotes cell survival $[5,9,10]$.

In 1993, the initial BCL-2 interaction partner, BAX, was recognized as a immensely homologous protein that might self-associate or heterodimerize with BCL-2, but in prominent contrast to BCL-2, it promoted, to a certain extent than blocked, cell death after a stress stimulus [7]. With the invention of BAX, the rheostat cell death model was formulated, positioning the BCL-2, and BAX as the dark side and light side of whose relative levels dictated the equilibrium between death and cellular life [7]. With this initial point, the aim of this study was to determine a comparative composite based structure of BAX of Chinese liver fluke and different structural analysis.

\section{METHODS}

Starting material, i.e., protein amino acid of BAX of Chinese liver fluke mined from National Centre for Biotechnology Information (http:// ncbi.nlm.nih.gov) [11]. SignalP 4.0 server was used for search of signal peptide signature within the protein sequence of BAX of Chinese liver fluke [12]. Molecular model of BAX of Chinese liver fluke protein was generated by the comparative composite modeling tool Iterative Threading ASSEmbly Refinement (I-TASSER) suite [13]. Afterward, 
I-TASSER generated molecular model was subjected to further structural improvements by energy minimization step by SwissPDB Viewer (GROMOS 96 43B1 parameters set) [14]. The validation for three-dimensional structural model obtained by comparative composite modeling approach was evaluated by PROCHECK tool and ProSA-web tool $[15,16]$. Distribution of negatively and positively charged amino acid over molecular modeled structure, distribution of secondary structural elements, and hydrophobicity molecular surface analysis was performed with the help of UCSF Chimera package [17]

\section{RESULTS AND DISCUSSION}

BAX is a main proapoptotic constituent of the BCL-2 family of protein and a molecule essential for cell death that is broadly expressed equally in small cell (SCLC) and non-small cell lung cancer (NSCLC) cells signifying that BAX possibly will be a therapeutic target designed for lung cancer $[18,19]$. Activation of BAX proapoptotic function is expected to occur through a number of interdependent mechanisms to facilitate its translocation from the cytosol to mitochondria [20], insertion, and oligomerization into mitochondrial membranes after cellular stress [21]. Earlier reports point out that the post-translational modification of the proapoptotic action of BAX can be controlled by phosphorylation [22].

In patients with lung cancer survival, chances are low due to resistance to conventional health-giving interventions [23]. Apoptotic initiation in cancer cells is a well-known example in cancer therapy. BAX has been recognized as a promising prognostic marker in lung cancer patients, signifying that it could potentially offer a beneficial target in patients with lung cancer [24]. In recent times, it has been known that in the c-terminal tail the S184 phosphorylation site of BAX functionally controls the proapoptotic action of BAX $[19,25]$.

BAX similar to any other three dimensional structure of its BCL-2 family proteins shows alike tertiary structures [26]. The center of the protein comprises of Helices $\alpha 5(\mathrm{H} \alpha 5)$ and $\mathrm{H} \alpha 6$ which are implanted within the further seven helices that are amphipathic and maintain their hydrophilic residues uncovered to the periphery [27]. $\mathrm{H} \alpha 5$ is known as mitochondria pore-forming domain and $\mathrm{H} \alpha 6$ known as transmembrane domain [28]. For the translocation of BAX to mitochondria, a mitochondrial addressing signal of $\mathrm{N}$-terminal $\mathrm{H} \alpha 1$ is believed to be necessary [29]. Recent bioinformatical research methods were very helpful for the discovery process of new biologically and biomedically important protein molecules [30-39]. Therefore, varied structural forms of BAX molecules in the different organisms (e.g., Chinese liver fluke) must be identified for bio-medical interventions.

Analysis of Ramachandran plot created by PROCHECK tool is a consensus standard for validation purpose of protein structural modeling. Ramachandran plot for BAX has been depicted in Fig. 1. Altogether $97.8 \%$ of the residues were detected in allowed and favored regions, which in turn validate the quality of generated protein structural model (Fig. 2). ProSA-web was employed to investigate three-dimensional model of BAX of Chinese liver fluke for possible errors. As shown in Fig. 3, the Z-score of BAX of Chinese liver fluke was -5.57 . The score was perfectly within the range of scores typically observed for proteins of corresponding size representing highly dependable three-dimensional structures.

Figs. 4 and 5 depict the distribution of positively and negatively charged amino acid over molecular modeled structure of BAX of Chinese liver fluke, respectively. Total negatively and positively charged residues within the BAX of Chinese liver fluke were 23 and 20, respectively.

Chimera package guided hydrophobicity molecular surface analysis (dodger blue for the most hydrophilic, to white, to orange-red for the most hydrophobic) which represents the molecular surface of protein, colored by amino acid hydrophobicity, illustrates that molecule

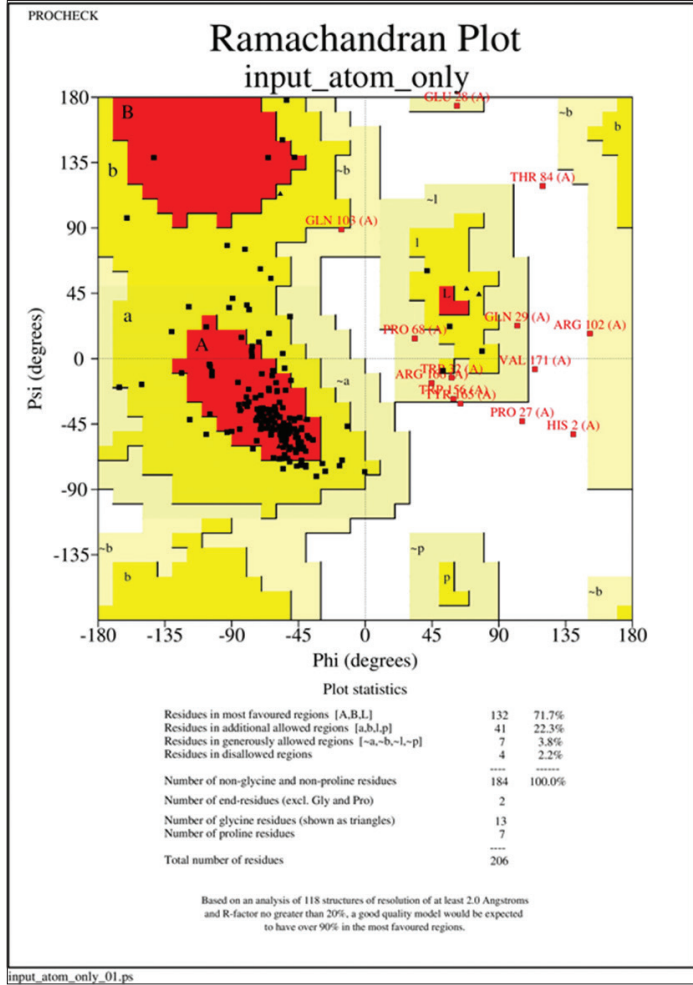

Fig. 1: Ramachandran plot (PROCHECK analysis) of molecular model of B-cell lymphoma 2-associated $\mathrm{X}$ protein of Chinese liver fluke

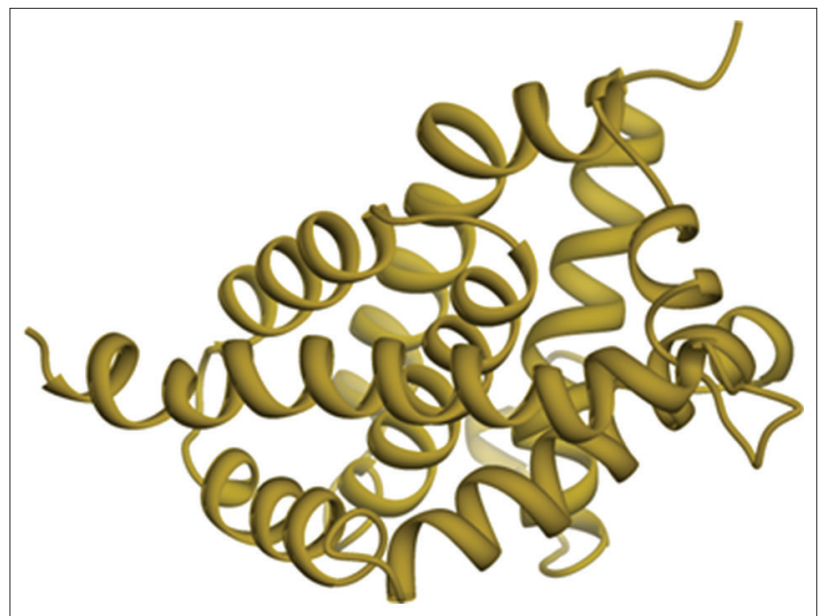

Fig. 2: Three-dimensional modeled structure of B-cell lymphoma 2 -associated $X$ protein of Chinese liver fluke

specific hydrophobicity surface is exclusive to BAX protein molecule in Fig. 6.

\section{CONCLUSION}

Within the scope of this scientific investigation, we have successfully utilized molecular modeling approach to suggest the first molecular three-dimensional model structure of BAX of Chinese liver fluke. The synchronous balance between cellular deaths and cellular life is keeping up by BAX, an important proapoptotic family member of BCL-2 family. Consequently, it would be an exciting approach to resolve its structural characterization and molecular structure to propose mode of mechanism action. Hence, a three-dimensional structural model of the $\mathrm{BAX}$ protein was generated. Additional investigation was performed to infer its molecular characteristics. 


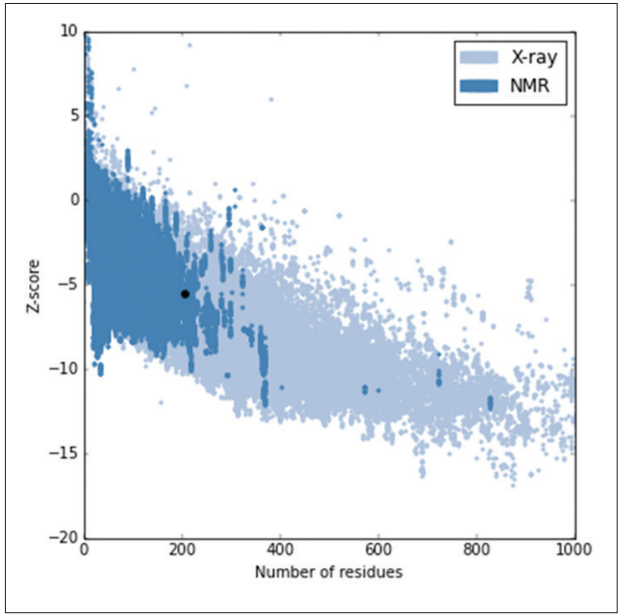

Fig. 3: ProSA-web analysis (Stereo-chemical validation) of modeled protein structure of B-cell lymphoma 2-associated X protein of Chinese liver fluke

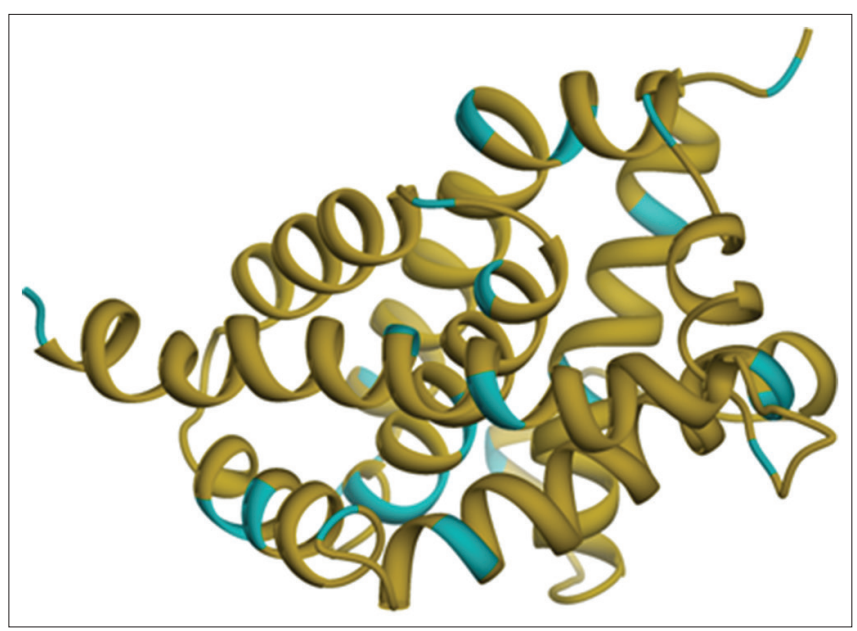

Fig. 4: Distribution of positively charged (blue) amino acid distribution within the B-cell lymphoma 2 -associated $\mathrm{X}$ protein of Chinese liver fluke

\section{ACKNOWLEDGMENT}

We are very thankful to Mrs. Susmita Chakraborty, Chairman, Trinity Trust, Asansol, West Bengal, Prof. Kalyan Kumar Sen, Principal, Gupta College of Technological Sciences, Aasnsol, West Bengal, for providing infrastructure facilities for carrying out the research work. Authors are greatly indebted to National Institute of Health (NIH) and National Center for Biotechnology Information (NCBI) for providing database support.

\section{REFERENCES}

1. Liu Z, Ding Y, Ye N, Wild C, Chen H, Zhou J. Direct activation of BAX protein for cancer therapy. Med Res Rev 2016;36(2):313-41.

2. Wu J, Ding Y, Chen CH, Zhou Z, Ding C, Chen H, et al. A new oridonin analog suppresses triple-negative breast cancer cells and tumor growth via the induction of death receptor 5. Cancer Lett 2016;380(2):393-402.

3. Wang W, Guo W, Li L, Fu Z, Liu W, Gao J, et al. Andrographolide reversed 5-FU resistance in human colorectal cancer by elevating BAX expression. Biochem Pharmacol 2016;121:8-17.

4. Walensky LD, Gavathiotis E. BAX unleashed: The biochemical transformation of an inactive cytosolic monomer into a toxic mitochondrial pore. Trends Biochem Sci 2011;36(12):642-52.

5. Pegoraro L, Palumbo A, Erikson J, Falda M, Giovanazzo B, Emanuel BS, et al. A 14;18 and an 8;14 chromosome translocation in a cell line derived from an acute B-cell leukemia. Proc Natl Acad Sci U S A $1984 ; 81(22): 7166-70$

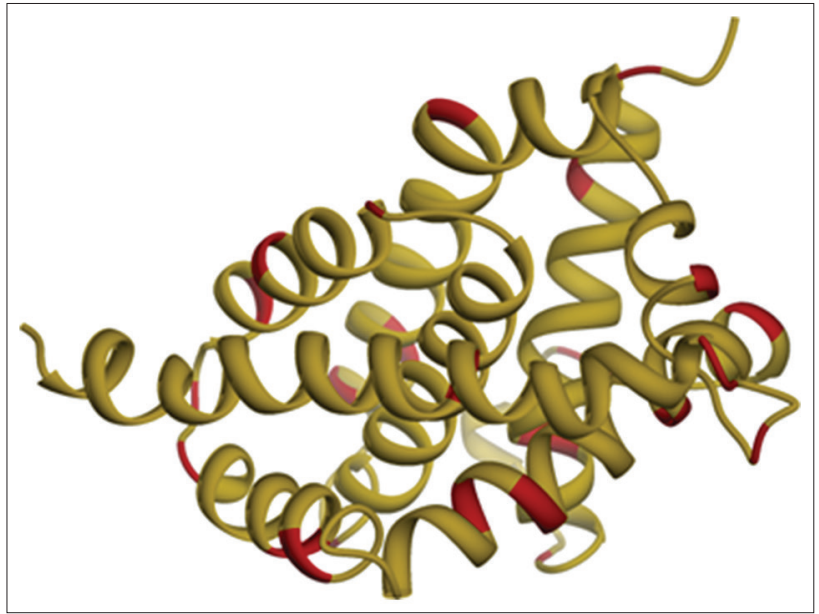

Fig. 5: Distribution of negatively charged (red) amino acid distribution within the B-cell lymphoma 2 -associated $\mathrm{X}$ protein of Chinese liver fluke

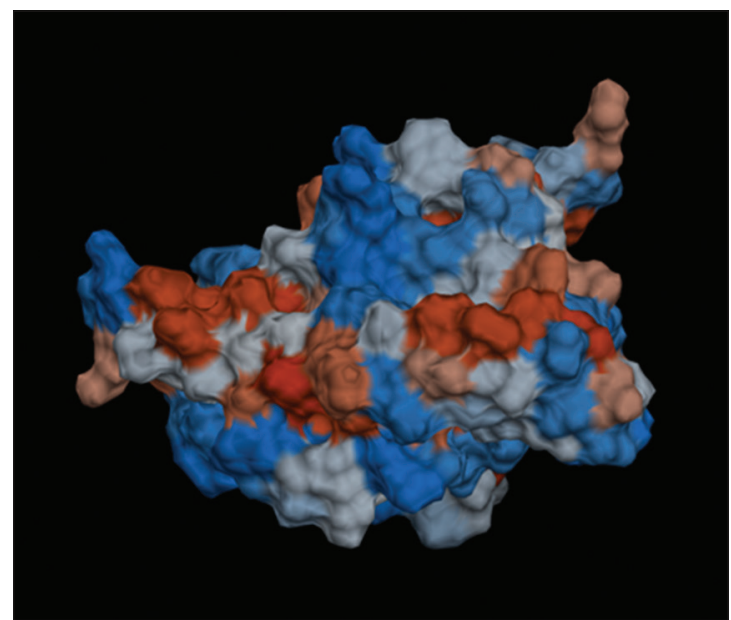

Fig. 6: Hydrophobicity surface maps of B-cell lymphoma 2-associated X protein of Chinese liver fluke (Dodger blue for the most hydrophilic, to white, to orange red for the most hydrophobic)

6. Bakhshi A, Jensen JP, Goldman P, Wright JJ, McBride OW, Epstein AL, et al. Cloning the chromosomal breakpoint of $\mathrm{t}(14 ; 18)$ human lymphomas: Clustering around $\mathrm{JH}$ on chromosome 14 and near a transcriptional unit on 18. Cell 1985;41(3):899-906.

7. Oltvai ZN, Milliman CL, Korsmeyer SJ. Bcl-2 heterodimerizes in vivo with a conserved homolog, BAX, that accelerates programmed cell death. Cell 1993;74(4):609-19.

8. Kozopas KM, Yang T, Buchan HL, Zhou P, Craig RW. MCL1, a gene expressed in programmed myeloid cell differentiation, has sequence similarity to BCL2. Proc Natl Acad Sci U S A 1993;90(8):3516-20.

9. McDonnell TJ, Deane N, Platt FM, Nunez G, Jaeger U, McKearn JP, et al. Bcl-2-immunoglobulin transgenic mice demonstrate extended B cell survival and follicular lymphoproliferation. Cell 1989;57(1):79-88.

10. Vaux DL, Cory S, Adams JM. Bcl-2 gene promotes haemopoietic cell survival and cooperates with c-myc to immortalize pre-B cells. Nature 1988;335(6189):440-2

11. NCBI Resource Coordinators. Database resources of the National Center for Biotechnology Information. Nucleic Acids Res 2015;43:D8-20.

12. Petersen TN, Brunak S, von Heijne G, Nielsen H. SignalP 4.0: Discriminating signal peptides from transmembrane regions. Nat Methods 2011;8(10):785-6.

13. Zhang Y. I-TASSER server for protein 3D structure prediction. BMC Bioinformatics 2008;9:40.

14. Guex N, Peitsch MC. SWISS-MODEL and the Swiss-PdbViewer: An environment for comparative protein modeling. Electrophoresis 1997; 18(15):2714-23. 
15. Laskowski RA, Macarthur MW, Moss DS, Thornton JM. PROCHECK: A program to check the stereochemical quality of protein structures. $\mathrm{J}$ Appl Crystallogr 1993;26(2):283-91.

16. Wiederstein M, Sippl MJ. ProSA-web: Interactive web service for the recognition of errors in three-dimensional structures of proteins. Nucleic Acids Res 2007;35:W407-10.

17. Pettersen EF, Goddard TD, Huang CC, Couch GS, Greenblatt DM, Meng EC, et al. UCSF Chimera--a visualization system for exploratory research and analysis. J Comput Chem 2004;25(13):1605-12.

18. Wei MC, Zong WX, Cheng EH, Lindsten T, Panoutsakopoulou V, Ross AJ, et al. Proapoptotic BAX and BAK: A requisite gateway to mitochondrial dysfunction and death. Science 2001;292(5517):727-30.

19. Xin M, Deng X. Nicotine inactivation of the proapoptotic function of BAX through phosphorylation. J Biol Chem 2005;280(11):10781-9.

20. Goping IS, Gross A, Lavoie JN, Nguyen M, Jemmerson R, Roth K, et al. Regulated targeting of BAX to mitochondria. J Cell Biol 1998;143(1):207-15.

21. Smaili SS, Hsu YT, Carvalho AC, Rosenstock TR, Sharpe JC, Youle RJ. Mitochondria, calcium and pro-apoptotic proteins as mediators in cell death signaling. Braz J Med Biol Res 2003;36(2):183-90.

22. Kim BJ, Ryu SW, Song BJ. JNK-and p38 kinase-mediated phosphorylation of BAX leads to its activation and mitochondrial translocation and to apoptosis of human hepatoma HepG2 cells. J Biol Chem 2006;281(30):21256-65.

23. Jemal A, Siegel R, Ward E, Murray T, Xu J, Thun MJ. Cancer statistics, 2007. CA Cancer J Clin 2007;57(1):43-66.

24. Groeger AM, Esposito V, Cassandro R, Baldi G, Rossiello L, De Luca L, et al. A model of BAX gene delivery to human lung cancer. Anticancer Res 2001;21(5):3627-30.

25. Xin M, Li R, Xie M, Park D, Owonikoko TK, Sica GL, et al. Smallmolecule BAX agonists for cancer therapy. Nat Commun 2014;5:4935.

26. Petros AM, Olejniczak ET, Fesik SW. Structural biology of the Bcl-2 family of proteins. Biochim Biophys Acta 2004;1644(2-3):83-94.

27. Lalier L, Cartron PF, Juin P, Nedelkina S, Manon S, Bechinger B, et al. BAX activation and mitochondrial insertion during apoptosis. Apoptosis 2007;12(5):887-96.
28. Annis MG, Soucie EL, Dlugosz PJ, Cruz-Aguado JA, Penn LZ, Leber $\mathrm{B}$, et al. BAX forms multispanning monomers that oligomerize to permeabilize membranes during apoptosis. EMBO J 2005;24(12):2096-103

29. Cartron PF, Priault M, Oliver L, Meflah K, Manon S, Vallette FM. The N-terminal end of BAX contains a mitochondrial-targeting signal. J Biol Chem 2003;278(13):11633-41.

30. Panda S, Kumari L. Discovery of an unexplored protein structural scaffold of serine protease from big blue octopus (Octopus cyanea): A new prospective lead molecule. Curr Drug Discov Technol 2017;17(2):1-4.

31. Panda S, Panda S, Kumari L. Molecular modeling and structural analysis of arylesterase of Ancylostoma duodenale. Int J Pharm Bio Sci 2016;7(3):B611-6.

32. Panda S, Chandra G. Sequence analysis and phylogenetic study of some toxin proteins of snakes and related non-toxin proteins of chordates. Bioinformation 2013;9(5):259-66.

33. Chandra G, Panda S. Molecular modeling and structural analysis of some snake venom specific toxin proteins and cognate non-toxin proteins of other chordates. Curr Drug Discov Technol 2017;14(1):59-69.

34. Panda S, Prasad D. Apoptosis regulator BAX of Chinese tree shrew (Tupaia belangeri Chinensis): Molecular modelling and structural characterization. Int J Pharm Bio Sci 2016;7(4):B747-52.

35. Panda S, Hazra S. Sequence analysis of serum paraoxonase 1 of bathyergidae family specific rats. Int J Pharm Bio Sci 2016;7(4):B702-6.

36. Panda S, Kumari L, Panda S. Structural understanding of cytotoxin 1 of Naja sputatrix: A potential anticancer agent. J Drug Deliv Ther 2016;6(3):59-63.

37. Panda S, Chandra G. Physicochemical characterization and functional analysis of some snake venom toxin proteins and related non-toxin proteins of other chordates. Bioinformation 2012;8(18):891-6.

38. Miladiyah I, Jumina J, Haryana SM, Mustofa M. In silico molecular docking of xanthone derivatives as cyclooxygenase-2 inhibitor agents. Int J Pharm Pharm Sci 2017;9(3):98-104.

39. Murthy VB, Chowdary M, Sucharitha. In silico prediction of deleterious and non-deleterious nsSNPs in CFTR gene variants. Int J Pharm Pharm Sci 2016;8(12):303-6. 